\title{
Using continuous GPS and absolute gravity to separate vertical land movements and changes in sea level at tide gauges in the UK
}

\author{
By F. N. Teferle ${ }^{1}$, R. M. Bingley ${ }^{1}$, S. D. P. Williams ${ }^{2}$, T. F. BakeR ${ }^{2}$ \\ AND A. H. Dodson ${ }^{1}$ \\ ${ }^{1}$ Institute of Engineering Surveying and Space Geodesy (IESSG), University of \\ Nottingham, Nottingham NG72RD, UK \\ ${ }^{2}$ Proudman Oceanographic Laboratory (POL), Joseph Proudman Building, 6 \\ Brownlow Street, Liverpool L3 5DA, UK
}

\begin{abstract}
Researchers investigating climate change have used historical tide gauge measurements from all over the world to investigate the changes in sea level that have occured over the last century or so. A high quality tide gauge record can enable such changes in sea level to be estimated with an acceptable level of uncertainty if several decades of data are used. However, such estimates are a combination of any true sea level variations and any vertical movements of the land at the specific tide gauge. For a tide gauge record to be used to determine the climate related component, it is therefore necessary to correct for the vertical land movement component of the observed change in sea level.

In 1990, the IESSG and POL started developing techniques based on the Global Positioning System (GPS) for measuring vertical land movements at tide gauges in the UK. This paper briefly reviews these early developments and shows how they led to the establishment of continuous GPS (CGPS) stations at a number of tide gauges. The paper then goes on to discuss the use of absolute gravity (AG), as an independent technique for measuring vertical land movements at tide gauges. The most recent results, from CGPS time series dating back to 1997 and AG time series dating back to $1995 / 6$, are then used to demonstrate the complementarity of these two techniques and their potential for providing site-specific estimates of vertical land movements at tide gauges in the UK.
\end{abstract}

Keywords: CGPS; absolute gravity (AG); tide gauge; vertical land movements; changes in sea level

\section{Introduction}

In 1990, 1995 and 2001, the Intergovernmental Panel on Climate Change (IPCC) reviewed the published evidence on the influence of global warming on sea levels (IPCC 1990, 1995, 2001). They found that global sea level had risen by 10 to 20 $\mathrm{cm}$ over the past century, with predictions indicating further rises of the order of up to $88 \mathrm{~cm}$ by 2100 . The evidence for the past century came from mean sea level (MSL) measurements obtained at tide gauges, which measure MSL with respect to 
a local tide gauge bench mark (TGBM). A high quality tide gauge record enables the secular change of MSL to be determined with a standard error of $\pm 0.5 \mathrm{~mm} / \mathrm{yr}$, if 30 years of data are used (Woodworth et al. 1999). However, it is impossible to distinguish between any true sea level variations and vertical movements of the land at the tide gauge. Hence, to measure the climate related component of changes in sea level using a tide gauge, the rate of any vertical land movements at the specific tide gauge must be determined.

In some parts of the world it is possible to make this correction based on models of glacial isostatic adjustment (GIA). However, GIA does not account for all of the vertical land movements occuring at all of the tide gauges in the world. The GPS came into operation in the 1980's. Although this system was primarily designed for use in navigation, the potential to determine and monitor the heights of TGBM's in a global reference frame, and hence relate the climate related component of changes in sea level at each tide gauge to changes in global sea level, was recognised as early as 1988. In 1988, the International Association for Physical Sciences of the Ocean (IAPSO) Commission on Mean Sea Level and Tides reviewed the geodetic fixing of TGBM's at a workshop held at the Woods Hole Oceanographic Institute, USA (Carter et al. 1989). The 'IAPSO Committee' recommended that TGBM's should be connected to the International Terrestrial Reference Frame (ITRF) and monitored through episodic GPS campaigns, with simultaneous measurements made at tide gauges and fundamental ITRF stations (Baker 1993). This meeting 'spawned' the first demonstrations of using GPS at tide gauges, through national projects such as UKGAUGE (Ashkenazi et al. 1993), which included the first GPS measurements at tide gauges in the UK, and regional projects such as EUROGAUGE (Ashkenazi et al. 1994) and SELF I (Zerbini et al. 1996).

In the years that followed the 'Woods Hole meeting' there were significant advances in GPS technology, with cheaper and more reliable GPS receivers available, the completion of the GPS satellite constellation and the establishment of the International GPS Service (IGS) (Zumberge et al. 1997). Hence, at a second workshop held at the Institute of Oceanographic Sciences, UK in 1993, the 'IAPSO Committee' recommended that continuous GPS (CGPS) stations should be installed at about 100 tide gauges world-wide. The objective was to form a core network of a 'global absolute sea level monitoring system', with regional densification of this core network carried out, through episodic GPS campaigns or the use of CGPS (Carter, 1994). Although this core network was not realized, through the IGS, GPS was firmly established as a technique to sit alongside Very Long Baseline Interferometry (VLBI) and Satellite Laser Ranging (SLR) in the realization of the International Terrestrial Reference System (ITRS). This could clearly be seen from the number of CGPS stations that contributed to successive realizations of the ITRS, which increased from about 50 in ITRF93 to over 200 in ITRF97 (Boucher et al. 1994, 1999).

By 1997, the advantages of using CGPS instead of episodic GPS had been demonstrated on a global scale by the IGS (Zumberge et al. 1997) and on a regional scale, e.g. in Fennoscandia (BIFROST 1996). The specific use of CGPS at tide gauges was discussed further at a third workshop held at the Jet Propulsion Laboratory in 1997, which was jointly organised by the IGS and the Permanent Service for Mean Sea Level (PSMSL) (Neilan et al. 1997). At this 'IGS/PSMSL meeting' the first experiences of using CGPS at tide gauges were reported; from 
Sheerness in the UK (Ashkenazi et al. 1997), Solomons Island in the Chesapeake Bay (Nerem et al. 1997) and Porto Corsini in the Mediterranean (Zerbini, 1997).

Since 1997, the IESSG and POL have been using CGPS to measure the vertical land movements at or close to tide gauges in the UK, with a current network of seven CGPS stations, about to expand to 13 over the next year. However, the use of GPS at tide gauges has proven to be not as straightforward as perhaps first imagined back in 1988. There are many issues to be considered when trying to monitor vertical land movements of millimetres per year, in order to decouple these from the true sea level variations in tide gauge records. All of these issues effectively relate to the accuracy and precision of the vertical station velocity estimates.

In terms of precision, it is essential that a realistic uncertainty is assigned to any estimate. Zhang et al. (1997) and Mao et al. (1999) and recently Williams et al. (2004) showed that CGPS coordinate time series contain both white noise and coloured noise. The result being that station velocity uncertainties may be underestimated if correlations in the form of coloured noise are not accounted for. Maximum-Likelihood estimation allows precise stochastic models to be fitted to CGPS coordinate time series whilst simultaneously estimating linear trend, periodic signals and coordinate offsets. Such techniques have been applied when analysing the coordinate time series for the CGPS stations at or close to tide gauges in the $\mathrm{UK}$, as detailed later in this paper.

In terms of accuracy, the role of absolute gravity (AG) is proving critical. Although mentioned in the report from the 'Woods Hole meeting' (Carter et al. 1989), the cost of instrumentation and the field effort required, when compared to GPS, meant that there was very little activity in terms of the use of AG at tide gauges until the mid 1990's, i.e. about five or six years after the first use of episodic GPS and almost coincident with the introduction of CGPS. Fortunately, in the UK, AG measurements were started close to three tide gauges in 1995 and 1996, as detailed in Williams et al. (2001). As this paper demonstrates, this has enabled an assessment of the vertical station velocity estimates based purely on CGPS, leading to the conclusion that through the combined use of CGPS and AG, it will be possible to obtain reliable estimates of the desired vertical land movements.

\section{CGPS at or close to tide gauges in the UK}

In this section, details of the CGPS network, the CGPS processing strategy and the CGPS coordinate time series analysis strategies are given.

\section{(a) The CGPS network}

During the period from 1997 to 1999, the IESSG and POL established CGPS stations at five tide gauges in the UK, namely Sheerness, Newlyn, Aberdeen, Liverpool and Lowestoft. The CGPS stations were installed such that the GPS antennas were sited as close as possible to the tide gauge, i.e. within a few metres of the tide gauge itself. A further two CGPS stations were established at the tide gauges of North Shields and Portsmouth in 2001; however, neither of these have been used in this study, which has focussed on those CGPS stations with the longest, continuous time series. 


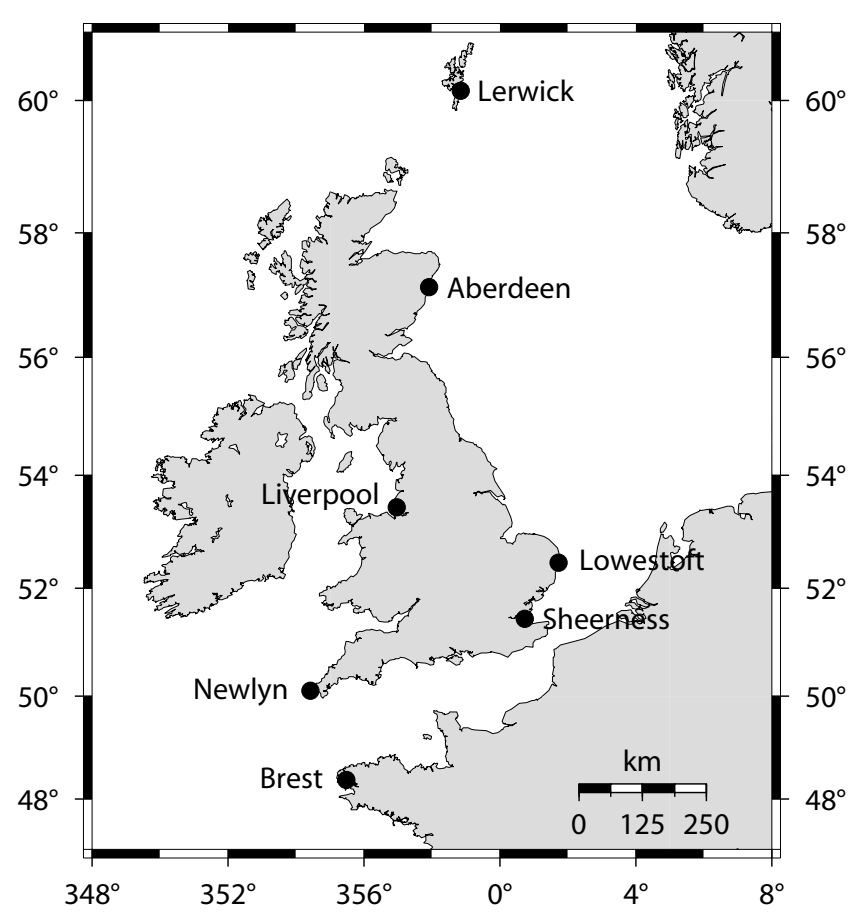

Figure 1. A map of the CGPS stations used in this study, that are close to or at tide gauge sites in the UK and northern France.

During 1998, several other CGPS stations were established by the IESSG and the Met Office, for the purpose of estimating integrated precipitable water vapour. One of these was on the Shetland Islands, located about $5 \mathrm{~km}$ from the tide gauge at Lerwick but with the GPS antenna mounted on a survey monument connected to a concrete block founded on 'solid rock'. To complement the five CGPS stations listed above, the CGPS station at Lerwick and the CGPS station at the Brest tide gauge in northern France, have also been used in this study, making a total of seven CGPS stations at or close to tide gauges (see figure 1).

\section{(b) CGPS processing and coordinate time series}

The processing for all of the CGPS stations shown in figure 1 has been carried out using the GPS Analysis Software (Stewart et al. 2002) developed at the IESSG. The results presented in this study are based on 24-hour, dual frequency GPS data for the period up to December 2003. All CGPS data were processed along with data from IGS stations at Kootwijk, Onsala, Villafranca and Wettzell. As a result, a series of loosely constrained daily solutions was obtained. These daily solutions used the IGS final ephemeris, the ionospherically free observable, no integer fixing of phase ambiguities, the estimation of tropospheric zenith delay parameters at 15 minute intervals, the IGS antenna phase center variation models, and corrections for both solid Earth tides and ocean tide loading according to IERS standards (McCarthy 1996). In order to form consistent coordinate time series for each of the CGPS stations, each loosely constrained daily solution was then constrained at the 
observation epoch, based on the ITRF2000 coordinates and velocities of the above IGS stations.

\section{(c) CGPS coordinate time series analysis}

For the CGPS coordinate time series, residual systematic effects due to unmitigated tropospheric delay, antenna phase center variations or loading processes, can remain in the daily height estimates. Furthermore, biases in the global reference frame and satellite orbits can also propagate into these height solutions. Not only do these effects increase and change the stochastic properties of the noise level (Zhang 1997, Mao 1999, Williams et. al. 2004), but they may also introduce artificial signals at the several mm-level in the height time series (Herring 2001, Altamimi et. al. 2002, Dong et. al. 2002).

Taking these facts into account, in order to obtain vertical station velocity estimates and realistic uncertainties from the CGPS results, the following multi-step coordinate time series analysis strategy has been carried out (Teferle 2003):

1. Computation of residual geocentric coordinate time series by removal of a linear trend from the outlier-cleaned, daily ITRF2000 geocentric coordinate time series.

2. Computation of the common mode bias using weighted stacking of the daily geocentric coordinate residuals.

3. Filtering of the daily ITRF2000 geocentric coordinate time series by removal of the daily common mode bias.

4. Transformation of the filtered geocentric coordinate time series to filtered topocentric coordinate time series.

5. A maximum-likelihood estimation (MLE) of the filtered, daily ITRF2000 height time series to simultaneously obtain estimates for a linear trend, annual signals, coordinate offsets and noise parameters.

The method of weighted stacking is essentially equivalent to a similarity transformation using only the three translation parameters. By filtering the height time series, spatial correlations in the regional CGPS network solutions are removed, improving the signal-to-noise ratio, which is especially important for the height component (Wdowinski et. al. 1997, Nikolaidis 2002, Wdowinski et al. 2004, Williams et. al. 2004). Furthermore, for the estimation of realistic uncertainties it is important to understand the time-correlated (colored) noise content of height time series, as the often quoted statistical uncertainties, assuming time-uncorrelated (white) noise, can lead to largely optimistic error bounds (Langbein \& Johnson 1997, Zhang 1997, Mao 1999). By using MLE, precise stochastic models have been fitted to the time series and the noise parameters have been estimated based on a white plus power-law noise model (Williams 2003, Williams et. al. 2004).

The resulting coordinate time series are shown in figure 2 .

\section{(d) Comparison of vertical station velocity estimates}

As can be seen from figure 2, all of the CGPS vertical station velocities are positive or zero and their uncertainties are in the range from \pm 0.2 to $\pm 0.7 \mathrm{~mm} / \mathrm{yr}$. A 


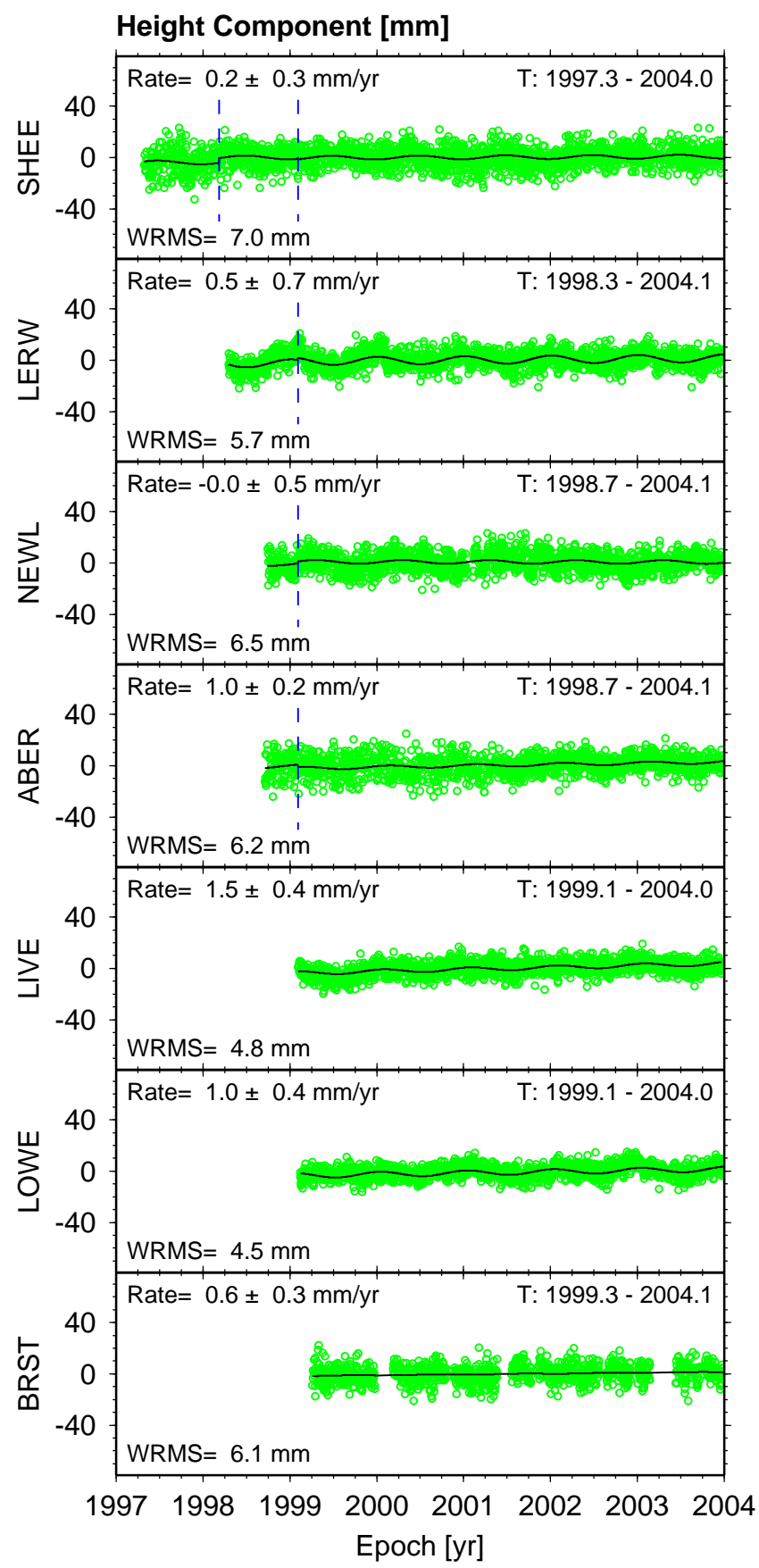

Figure 2. CGPS common-mode filtered ITRF2000 height time series and vertical station velocity estimates based on a maximum-likelihood estimation (MLE) using a white plus power-law noise model. 
Lerwick $0.2 \pm 0.2 \mu \mathrm{gal} / \mathrm{yr}[-1.1 \pm 1.1 \mathrm{~mm} . \mathrm{yr}]$

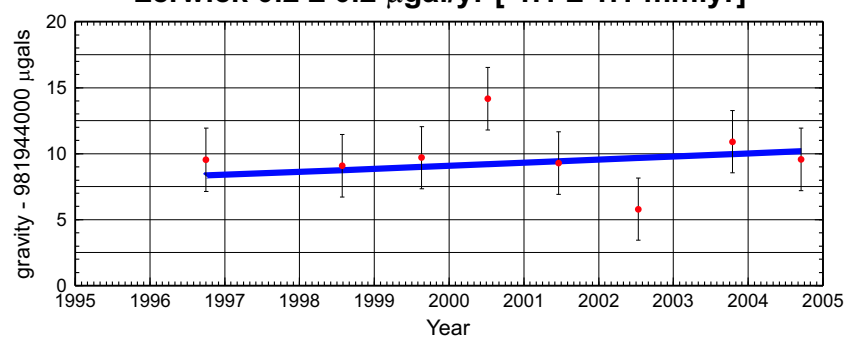

Newlyn $0.1 \pm 0.2 \mu \mathrm{gal} / \mathrm{yr}[-0.5 \pm 0.9 \mathrm{~mm} / \mathrm{yr}]$

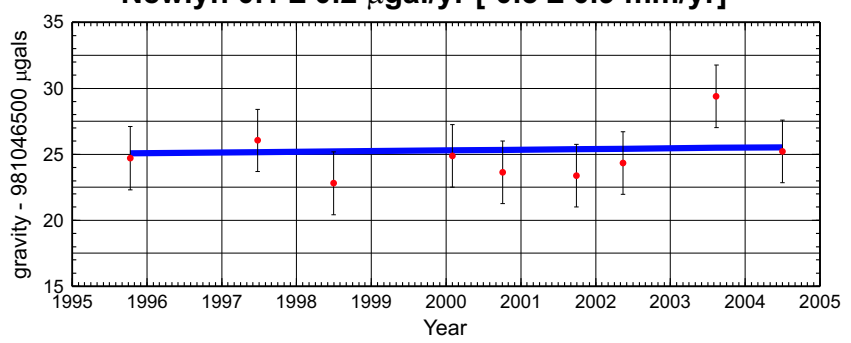

Figure 3. AG time series, with vertical station velocity estimates given in the square brackets.

comparison of the CGPS vertical station velocities to values previously published is possible for Brest. For Brest, Sella et. al. (2002) and (Boucher et. al. 2004) reported values of $-4.2 \pm 3.4 \mathrm{~mm} / \mathrm{yr}$ and $-3.4 \pm 2.3 \mathrm{~mm} / \mathrm{yr}$, respectively. In both cases the large uncertainties are indicative of a much shorter observation time span compared to this analysis and the magnitude of subsidence is clearly not supported by the MSL trend for Brest, which is $1.0 \pm 0.1 \mathrm{~mm} / \mathrm{yr}$ (PSMSL, 2002).

\section{AG close to tide gauges in the UK}

POL began to make AG measurements near the tide gauges at Newlyn and Aberdeen in 1995 and at Lerwick in 1996 (Williams et. al. 2001). These measurements are being made with the POL absolute gravimeter FG5-103, manufactured by Micro-g Solutions Inc., USA. A value of gravity is obtained every 10s by dropping a test mass in a vacuum and using an Iodine stabilised He-Ne laser interferometer and rubidium atomic clock to obtain distance-time pairs and solve the equations of motion (Niebauer et. al. 1995). AG measurements are taken for typically 3 to 4 days every year at each site. The sites were chosen to be on bedrock and FG5-103 is regularly inter-compared with other instruments in Europe and the USA to ensure that it gives consistent results at the 1 to 2 microgal level (Williams et. al. 2001).

The time series of AG values at Newlyn and Lerwick are of particularly high quality and are used in the present work (see figure 3). The uncertainties in the linear trends have been determined by combining an instrumental set-up error with a Gauss-Markov model for the coloured noise (Van Camp et. al. 2004). 
Table 1. Vertical land movements comparison

(All figures shown are in mm/yr.)

\begin{tabular}{lccrrrr}
\hline Station & CGPS & AG & Geology & -(MSL-GSL) & GIA L & GIA P \\
\hline Sheerness & $0.2 \pm 0.3$ & & -0.7 & -0.6 & -0.5 & -0.2 \\
Newlyn & $0.0 \pm 0.5$ & $-0.5 \pm 0.9$ & -1.1 & -0.2 & -1.0 & -0.3 \\
Aberdeen & $1.0 \pm 0.2$ & & 0.7 & 0.8 & 0.0 & 0.6 \\
Lerwick & $0.5 \pm 0.7$ & $-1.1 \pm 1.1$ & & 2.5 & -1.8 & -0.5 \\
Liverpool & $1.5 \pm 0.4$ & & -0.2 & 0.1 & -0.3 & 0.4 \\
Lowestoft & $1.0 \pm 0.4$ & & -0.6 & -0.5 & -0.5 & -0.4 \\
Brest & $0.6 \pm 0.3$ & & & 0.5 & -0.9 & -0.3 \\
\hline
\end{tabular}

\section{Vertical land movements comparison}

Especially for the British Isles a number of alternative, high quality and independent evidence of vertical land movement (VLM) have been published. These data include, estimates based on: geological information (Shennan \& Horton 2002), styled as Geol.; mean sea level (MSL) trends from the tide gauge measurements at each site (Woodworth et. al. 1999, PSMSL 2002) with an assumed global sea level rise of $1.5 \mathrm{~mm} / \mathrm{yr}$, styled as -(MSL-GSL); glacial isostatic adjustment models, e.g. Lambeck \& Johnston (1995), Peltier (2001), styled as GIA L and GIA P respectively. Table 1 shows the independent estimates along with the values obtained from CGPS and AG.

From table 1 , it is clear that there is generally good agreement between the estimates of VLM based on geology, tide gauges and GIA models, at all sites except Brest and Lerwick. Taking the estimates based on AG into account, these would seem to suggest that the anomaly at Lerwick is in the tide gauge measurements, which only began in the 1960s and show a fall of mean sea level that is most likely related to the anomalous North Atlantic Oscillation (NAO) index from the 1960s to 1990 s.

From table 1, however, it is also clear that the CGPS estimates of VLM are systematically offset from the AG estimates of VLM and the estimates of VLM from the other independent evidence. At this point, it is worth discussing the nature of this offset, by considering whether such indepdendent estimates should be in agreement in the first place. Consider the following two statements: 'The Earth has a mass geocentre, which is in itself not stationary, due to real movements of mass, for example from ice sheets to ocean' and 'sea level changes with respect to the real geocentre, due to gravitational forces'.

The ITRF2000 reference frame, in which the CGPS processing is carried out, has a geocentre that is defined as the 'Center of Mass of the Earth System (CM)', based on Satellite Laser Ranging (SLR). However, the CGPS estimates given in this paper are effectively referenced to their own realisation of the ITRF2000 reference frame and, hence, their own definition of CM, which depends mostly on the subset of IGS stations constrained in ITRF2000, partly on the fact that the IGS final orbit is in its own reference frame that is not exactly in ITRF2000 and partly due to subtle changes caused by the common-mode filtering carried out as part of the CGPS coordinate time series analysis (Wdowinski et al. 2004). Hence, the CGPS estimates could be offset from the 'truth' because the geocentre implied by 
the regional network solutions is not identical to the geocentre of ITRF2000, and because the geocentre of ITRF2000 is not coincident with the real geocentre.

The various sources of independent evidence are also related to their own definition of CM, because of their dependence on either sea level or gravity, and are often considering changes that have occurred over a much longer time scale:

- The AG estimates are based on absolute gravity measurements for the past few years.

The Geol. estimates are effectively based on changes in sea level for the last 10,000 years, assuming no net global melting for the last 3,000 to 4,000 years.

- The -(MSL-GSL) estimates are based on tide gauge measurements for the last few decades.

- The GIA L and GIA P estimates are based on GIA models for the last 10,000 years, that are initially referred to the 'Centre of mass of the Solid Earth (CE)' but are constrained by geological sea level measurements. Hence, these estimates could be offset from the 'truth' because the geocentre implied by their technique is not coincident with the real geocentre.

Going back to table 1, it would appear that, despite the differences in time periods, the AG estimates of VLM are more closely aligned than the CGPS estimates of VLM, to the estimates of VLM from the other independent evidence. Considering the CGPS estimates and the AG estimates on their own, it would appear that the CGPS estimates are systematically offset from the AG estimates, which are independent of the reference frame used by GPS.

Similar offsets of CGPS estimates of VLM from independent evidence have recently also been reported by Prawirodirdjo \& Bock (2004) and MacMillan (2004). The analysis of the global CGPS network shows offsets for stations in North America and northern Europe between CGPS and GIA P estimates on average of 1.1 and $1.7 \mathrm{~mm} / \mathrm{yr}$, respectively (Prawirodirdjo \& Bock 2004). These findings are substantiated by a comparison of estimates of VLM from VLBI (Very Long Baseline Interferometry) and CGPS, which shows the CGPS estimates to be on average $1.5 \mathrm{~mm} / \mathrm{yr}$ greater than the VLBI estimates of VLM (MacMillan, 2004).

\section{Combining CGPS and AG for tide gauges in the UK}

Using weighted least-squares and data for Newlyn and Lerwick it is possible to compute an offset of $1.0 \pm 0.8 \mathrm{~mm} / \mathrm{yr}$ between the VLM estimates based on CGPS and those based on AG. Clearly the uncertainty in this offset is still quite large, due mainly to the large uncertainties in the AG measurements at this stage. However, the separate values of 0.5 and $1.6 \mathrm{~mm} / \mathrm{yr}$ suggest that the offset is systematic.

The comparisons with other independent evidence suggest that there may be a systematic bias in the vertical station velocity estimates and the VLM inferred from the CGPS height time series. At this stage, therefore, the combination of CGPS and AG for tide gauges in the UK has been effected by 'aligning' the CGPS estimates of VLM to the AG estimates. 


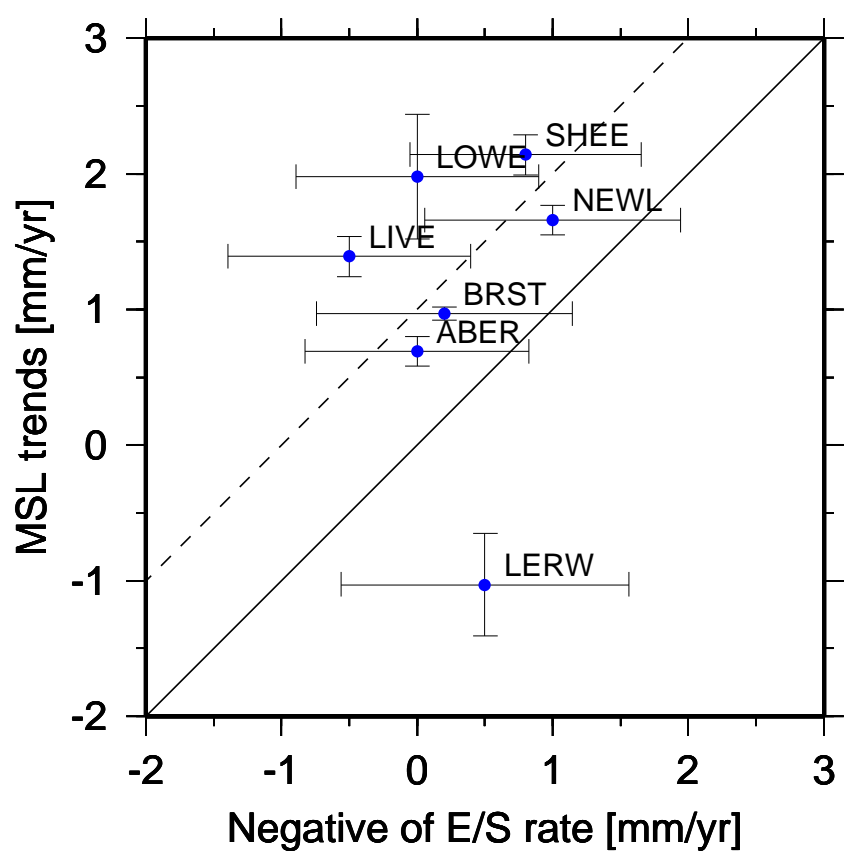

Figure 4. Relative MSL trends for seven tide gauges compared with the negative of the vertical station velocity estimates (emergence/submergence rates) based on AG-aligned CGPS. Data points on the dashed line would imply a sea level rise of $1.0 \mathrm{~mm} / \mathrm{yr}$

\section{(a) Computing a sea level rise}

The relative MSL trends and the 'AG-aligned CGPS estimates of VLM' have been used to compute an estimate of sea level rise for the British Isles. Figure 4 shows the relative MSL trends compared to the negative of the AG-aligned CGPS estimates of VLM.

The Lerwick tide gauge measurements only began in the 1960s and show a fall of mean sea level, which appears to be related to the anomalous NAO index from the 1960s to 1990s, as discussed in section 4. Considering Sheerness, Newlyn, Aberdeen, Liverpool, Lowestoft and Brest, a sea level rise of $1.1 \pm 0.7 \mathrm{~mm} / \mathrm{yr}$ is obtained. However, only using data for Sheerness, Newlyn, Aberdeen and Brest gives a sea level rise of $0.6 \pm 0.2 \mathrm{~mm} / \mathrm{yr}$., and only using data from Liverpool and Lowestoft gives a sea level rise of $1.9 \pm 0.1 \mathrm{~mm} / \mathrm{yr}$.

\section{The UK Contribution to European and Global Initiatives}

In Europe, Baker et al. (1997) first proposed a European network for sea and coastal land level monitoring. At about the same time, the 'IGS/PSMSL meeting' took place (Neilan et al. 1997) and Working Group 1 of the European Commission COST Action 40: European sea level observing system (EOSS) started to address the issues that relate to the use of CGPS at tide gauges (Plag et al. 2000). Ultimately, these have led to two definitive actions; on a European scale, ESEAS - the European Sea Level Service (www.eseas.org), and on a global scale, IGS TIGA - the IGS GPS Tide Gauge Benchmark Monitoring Pilot Project (op.gfz-potsdam.de/tiga/). Of the 
CGPS@TG stations in Britain that are detailed in this paper, all have contributed data from 1 January 2000 onwards to ESEAS and three (namely Newlyn, Sheerness and Aberdeen) have contributed all of their data to IGS TIGA.

\section{Conclusions}

This paper provides a summary of the research that is on-going in relation to the use of CGPS and AG for measuring vertical land movements at tide gauges in the UK. The most recent results, from CGPS time series dating back to 1997 and AG time series dating back to $1995 / 6$, have been used to demonstrate the complementarity of these two techniques, and a series of AG-aligned CGPS estimates of vertical land movements have been computed for seven tide gauges. An initial comparison between these estimates of vertical land movements and changes in relative MSL observed by the tide gauges, suggests a sea level rise around the British Isles of between 0.6 and $1.9 \mathrm{~mm} / \mathrm{yr}$.

Clearly, the statistical significance of such results cannot be assured as yet, due to the level of the uncertainties in the CGPS and AG time series. However, these should reduce as the time series are extended into the future, enabling site-specific estimates of vertical land movements and changes in sea level for tide gauges in the UK. Furthermore, the alignment procedure demonstrated in this paper, should enable multiple CGPS stations to be deployed without the need for simultaneous AG measurements at each site.

This research was funded by the Department for Environment Food and Rural Affairs (Defra) R\&D Projects FD2301 and FD2319. The CGPS data were taken from BIGF British Isles GPS archive Facility (www.bigf.ac.uk) funded by the Natural Environment Research Council (NERC).

\section{References}

Altamimi, Z., Sillard, P. \& Boucher, C. 2002 ITRF2000: A new release of the International Terrestrial Reference Frame for Earth science applications. J. Geophys. Res., 107 (B10), ETG 2-1 to ETG 2-19.

Ashkenazi, V., Bingley, R. M., Whitmore, G. M. \& Baker, T. F. 1993 Monitoring changes in mean-sea-level to millimetres using GPS. Geophys. Res. Lett., 20 (18), 1951-1954.

Ashkenazi, V., et al. 1994 EUROGAUGE: The west European tide gauge monitoring project. In Proc. INSMAP 94: International Symposium on Marine Positioning, Hannover, Germany, 19-23 September 1994.

Ashkenazi, V., Bingley, R. M., Dodson, A. H., Penna, N. T. \& Baker, T. F. 1997 Monitoring vertical land movements at tide gauges in the UK. In Proceedings of the workshop on methods for monitoring sea level: GPS and tide gauge benchmark monitoring and altimeter calibration. Jet Propulsion Laboratory, California Institute of Technology, Pasadena, California, JPL-Publication 97-017.

Baker, T. F. 1993 Absolute sea level measurements, climate change and vertical crustal movements. Global and Planetary Change, 8, Elsevier Science Publishers B V, 149-159.

Baker, T. F., Woodworth, P. L., Blewitt, G., Boucher, C. \& Woppelmann, G. 1997 A European network for sea and coastal land level monitoring. Journal of Marine Systems, 13, 163-171.

BIFROST Project Members 1996 GPS measurements to constrain geodynamics processes in Fennoscandia. EOS Transactions 77, 337\&341. 
Boucher, C., Altamimi, Z. \& Duhem, L. 1994 Results and analysis of the ITRF93. International Earth Rotation Service (IERS), Technical Note 18, Observatoire de Paris.

Boucher, C., Altamimi, Z. \& Sillard, P. 1999 Results and analysis of the ITRF97. International Earth Rotation Service (IERS), Technical Note 27, Observatoire de Paris.

Boucher, C., Altamimi, Z., Sillard, P. \& Feissel-Vernier, M. 2004 The ITRF2000. International Earth Rotation Service (IERS), Technical Note 31, Verlag des Bundesamts für Kartographie und Geodäsie, Frankfurt am Main.

Carter, W. E., et al. 1989 Geodetic fixing of tide gauge benchmarks. Woods Hole Oceanographic Institute Technical Report, WHOI-89-31.

Carter, W. E. (ed) 1994 Report of the Surrey workshop of the IAPSO tide gauge bench mark fixing committee, held at the Institute of Oceanographic Sciences, UK. NOAA Technical Report, NOSOES0006.

Dong, D., Fang, P., Bock, Y., Cheng, M. K. \& Miyazaki, S. 2002 Anatomy of apparent seasonal variations from GPS derived site position time series. J. Geophys. Res., 107 (B4), ETG-9-1 to ETG-9-16, 2002.

Herring, T. A. 2001 Vertical reference frame for sea level monitoring. EOS Trans. AGU, 82 (47), Fall Meet. Suppl., G31D-07, 2001.

IPCC, 1990 Scientific assessment of climate change. Cambridge University Press.

IPCC, 1995 Climate change 1995: the science of climate change. Cambridge University Press.

IPCC, 2001 Climate change 2001: the scientific basis. Cambridge University Press.

Lambeck, K. \& Johnston, P. J. 1995 Land subsidence and sea-level change: Contributions from the melting of the last great ice sheets and the isostatic adjustment of the Earth, in Land Subsidence, edited by Barends, Brouwer, and Schroeder, 3-18, Balkema, Rotterdam.

Langbein, J. \& Johnson, H. O. 1997 Correlated errors in geodetic time series: Implications for time-dependent deformation. J. Geophys. Res., 102 (B1), 591-603.

MacMillan, D. S. 2004 Rate Difference Between VLBI and GPS Reference Frame Scales. Eos Trans. AGU, 85 (47), Fall Meet. Suppl., Abstract G21B-05.

Mao, A., Harrison, C. G. A. \& T. H. Dixon 1999 Noise in GPS coordinate time series. J. Geophys. Res., 104 (B2), 2797-2818.

McCarthy, D. D. 1996 IERS Conventions (1996). IERS Technical Note 21, Central Bureau of IERS, Observatoire de Paris.

Neilan, R. E., Van Scoy, P. A. \& Woodworth, P. L. (eds) 1997 Proceedings of the workshop on methods for monitoring sea level: GPS and tide gauge benchmark monitoring and altimeter calibration. Jet Propulsion Laboratory, California Institute of Technology, Pasadena, California, JPL-Publication 97-017.

Nerem, R. S., vanDam, T. M. \& Schenewerk, M. S. 1997 A GPS network for monitoring absolute sea level in the Chesapeake Bay: BAYONET. In Proceedings of the workshop on methods for monitoring sea level: GPS and tide gauge benchmark monitoring and altimeter calibration. Jet Propulsion Laboratory, California Institute of Technology, Pasadena, California, JPL-Publication 97-017.

Niebauer, T. M., Sasegawa, G. S., Faller, J. E., Hilt, R. \& Klopping, F 1995 A new generation of absolute gravimeters. Metrologia, 32, 159-180.

Nikolaidis, R. M. 2002 Observation of geodetic and seismic deformation with the Global Positioning System. PhD thesis, University of California.

Peltier, W. R. 2001 ICE4G (VM2) glacial isostatic adjustment corrections. In Sea Level Rise History and Consequences. International Geophysics Series, Vol. 75, Academic Press, San Diego, 65-96. 
Plag, H. P., Axe, P., Knudsen, P., Richter, B. \& Verstraeten, J. 2000 European Sea-Level Observing Systems (EOSS): status and future developments. European Commission Publication EUR 19682.

Prawirodirdjo, L. \& Bock, Y. 2004 Instantaneous global plate motion model from 12 years of continuous GPS observations. J. Geophys. Res., 109 (8), B08405.

PSMSL 2002. Table of MSL secular trends derived from PSMSL RLR data.

Sella, G. F., Dixon, T. H. \& and Mao, A 2002 REVEL: A model for recent plate velocities from space geodesy, J. Geophys. Res., 107 (B4), ETG-11-1 to ETG-11-32.

Shennan, I. \& Horton, B. 2002 Holocene land- and sea-level changes in Great Britain, J. Quaternary Sci., 17 (5-6), 511-526.

Stewart, M. P., Ffoulkes-Jones, G. H., Ochieng, W. Y., Shardlow, P. J., Penna, N. T. \& Bingley, R. M. 2002 GAS: GPS Analysis Software version 2.4 user manual, IESSG, University of Nottingham, Nottingham, U.K.

Teferle, F. N. 2003 Strategies for long-term monitoring of tide gauges with GPS. PhD thesis, University of Nottingham.

Van Camp, M., Williams, S. D. P. \& Francis, O. 2004 Precision and accuracy of absolute gravity measurements. Submitted to JGR.

Wdowinski, S., Bock, Y., Zhang, J., Fang, P. \& Genrich, J. 1997 Southern California Permanent GPS Geodetic Array: Spatial filtering of daily positions for estimating coseismic and postseismic displacements induced by the 1992 Landers earthquake. J. Geophys. Res., 102 (B8), $18057-18070$.

Wdowinski, S., Bock, Y., Baer, G., Prawirodirdjo, L., Bechor, N., Naaman, S., Knafo, R., Forrai, Y., \& Melzer, Y. 2004 GPS measurements of current crustal movements along the Dead Sea Fault, J. Geophys. Res., 109 (B05403), 1-16

Williams, S. D. P. 2003 The effect of coloured noise on the uncertainties of rates estimated from geodetic time series. J. Geodesy, 76 (9-10), 483-494.

Williams, S. D. P., Baker, T. F. \& Jeffries, G. 2001 Absolute gravity measurements at UK tide gauges. Geophys. Res. Lett., 28 (12), 2317-2320.

Williams, S. D. P., Bock, Y., Fang, P., Jamason, P., Nikolaidis, R. M., Prawirodirdjo, L., Miller, M. \& and Johnson, D. J. 2004 Error analysis of continuous GPS position time series. J. Geophys. Res., 109 (B3), 1-19.

Woodworth, P. L., Tsimplis, M. N., Flather, R. A. \& Shennan, I. 1999 A review of the trends observed in British Isles mean sea level data measured by tide gauges. Geophysical Journal International 136, 651-670.

Zerbini, S., et al. 1996 Sea level in the Mediterranean: a first step towards separation of crustal movements and absolute sea level variations. Global and Planetary Change 14, $1-48$.

Zerbini, S. 1997 The SELF II project. In Proceedings of the workshop on methods for monitoring sea level: GPS and tide gauge benchmark monitoring and altimeter calibration. Jet Propulsion Laboratory, California Institute of Technology, Pasadena, California, JPL-Publication 97-01\%.

Zhang, J., Bock, Y., Johnson, H. O., Fang, P., Williams, S. D. P., Genrich, J., Wdowinski, S. \& Behr, J. 1997 Southern California Permanent GPS Geodetic Array: Error analysis of daily position estimates and site velocities. J. Geophys. Res., 102 (B8), 1803518055 .

Zumberge, J. F., Fulton, D. E. \& Neilan, R. E. (eds) 1997 International GPS Service for Geodynamics 1996 Annual Report. Jet Propulsion Laboratory, California Institute of Technology, Pasadena, California, JPL-Publication 97-020. 